\title{
IAEA Nuclear Science and Instrumentation Laboratory: Support to IAEA Member States and Recent Developments
}

\author{
F. FOULON, H. BEN ABDELOUAHED, M. BOGOVAC, S. CHARISOPOULOS, M. MATOS, A. MIGLIORI, R. PADILLA- \\ ALVAREZ, N. PESSOA BARRADAS, D. RIDIKAS, A. SIMON, N. SKUKAN, P. SLADEK, I. SWAINSON
}

\begin{abstract}
Physic Section, Division of Physical and Chemical Sciences, Department of Nuclear Sciences and Applications International Atomic Energy Agency, Austria nsil@iaea.org
\end{abstract}

\begin{abstract}
As part of the International Atomic Energy Agency's (IAEA) Physics Section, the Nuclear Science and Instrumentation Laboratory (NSIL) helps Member States (MSs) to establish, operate and maintain various nuclear instrumentation and spectrometry techniques in support of a wide range of applications such as health care, food, agriculture, environment, forensics, cultural heritage, and materials science. NSIL is contributing to capacity building, transfer of knowledge and expertise sharing, including the development of instruments and validation of analytical methodologies. This paper describes NSIL's key activities and provides an overview of the recent developments and achievements, including the commissioning and utilization of an end-station at one of the beam lines in Elettra Sincrotrone Trieste (EST, Italy), the upgrade of an ultralight radiation monitoring system onboarded on a drone, as well as the development of a full field $\mathrm{X}$-ray fluorescence analytical system for forensic applications and characterization of valuable art/archaeological objects.
\end{abstract}

Keywords - nuclear, instrumentation, training, spectrometry, gamma radiation monitoring, X-ray Fluorescence, Ion Beam Analysis, Synchrotron -based- X-ray spectrometry, neutron generator.

\section{INTRODUCTION}

Through the Nuclear Science Programme the IAEA carries out activities to assist and advise IAEA Member States (MSs) in assessing their needs for capacity building, research and development in the field of nuclear instrumentation and its applications, as well as supports MSs' activities for deriving socio-economic benefits in different fields.

The IAEA Nuclear Science and Instrumentation Laboratory (NSIL) belongs to the Physics Section which is one of the four sections of the Division of Physical and Chemical Sciences (NAPC), within the Department of Nuclear Sciences and Applications (NA). One of the primary goals of the Physics Section is to support MSs in establishing frameworks for the efficient and sustainable use of advanced nuclear technologies and associated instrumentation at particle accelerators, research reactors, and experimental fusion devices. The relevant activities fall into the IAEA's nuclear power, fuel cycle and nuclear sciences programme.

Over the last 20 years, the NSIL has contributed to capacity building in a wide range of applications. It has fostered the effective utilization of nuclear instrumentation and nuclear spectrometry techniques based on a variety of laboratory and portable instrumentation. Capacity building activities, described in $\S$ II, include the implementation of scientific visits and training activities, the dissemination of knowledge and competencies, the development of training documents, e-learning courses and manuals, as well as the organization of proficiency tests.

NSIL is performing adaptative research and development targeted at specific needs of the MSs. This includes the development of instruments, data acquisition systems, as well as analytical tools and methodologies. Recent achievements, described in $\S$ III, include the development of ultra-light gamma radiation monitoring systems onboarded on Unmanned Aerial Vehicles (UAVs) for environmental monitoring and a full-field XRF spectrometer to be used for non-destructive analysis of crime scene evidences in support of forensic investigations and the characterization of valuable objects from art and archaeological origin.

NSIL is involved in the development and operation of dedicated measurement chambers at beam lines of the Elettra Sincrotrone Trieste (EST, Italy) and the ion beam accelerator at the Ruđer Bošković Institute (RBI, Zagreb, Croatia), as described in $\S$ IV. The access of researchers from MSs to such facilities is facilitated through the organization of Coordinated Research Projects (CRPs) and through bilateral agreements with the partner facilities.

NSIL intend to expand its fields of work by installing a neutron science facility and is also seeking support to install a compact ion beam accelerator on its premises. The deployment of the neutron facility based on the use of two neutron generators, one Deuterium-Deuterium (DD) and one Deuterium-Tritium (DT) is described in $\S \mathrm{V}$.

A comprehensive feasibility study has been performed in 2018 to assess the need for the installation of an ion beam accelerator in Seibersdorf for capacity building as well as the provision of services across many fields of relevance to the IAEA and its MSs. The main conclusions of this feasibility study are summarized in $\S$ VI.

\section{CAPACITY BUILDING ACTIVITIES}

The successful use of nuclear technology depends on reliable instruments, monitoring and diagnostic equipment that allow the accurate measurement of both natural and manmade radiation in a very broad range of applications. Capacity building is essential to provide the users and developers with the appropriate knowledge, competences and skills to conduct their activities in a safe and reliable way. Capacity building 
activities are mainly supported through the IAEATechnical Cooperation (TC) programme but also through training activities organized within NSIL projects.

Organization of IAEA Conferences and Technical and Consultancy Meetings is used to collect and exchange knowledge and information related to a specific topic. This can give rise to IAEA publications such as Technical Documents (TECDOC) addressing and sharing the state of the art in various domains. Recent publications include Instrumentation for Digital Nuclear Spectroscopy [1] and New Technologies for Design, Modernization and Automation of Nuclear Application Related Systems and Processes [2]. E-learning materials are also increasingly developed, providing either an introduction or comprehensive insight into given topics: in-situ techniques for radiological characterization of sites [3], X-ray emission spectroscopy [4], both currently under final testing by a community of users, Neutron Activation Analysis, including gamma spectroscopy [5], and Strategic Planning for National Nuclear Institutions [6].

Another important tool in providing assistance in capacity building to MSs is the organization of Scientific Visits (SV) to NSIL or to experienced institutions. Such visits, with typical duration of one to two weeks, are used to share experience and expertise in the implementation of a specific project or instrumentation. For example, a recent SV at NSIL was targeted at providing assistance to the establishment of a nuclear science and technology Bachelor Study Programme and associated nuclear instrumentation laboratory in Rwanda. Another SV from Syria aimed to exchange information and good practices on the use of XRF techniques for the characterization of cultural heritage objects.

NSIL is organizing or co-organizing a broad range of training activities, starting from basic level training courses to advanced and specialized trainings. Most of these activities are organized in the frame of the TC programme, addressing various techniques, applied to a wide range of topics, including design of customized instruments, environmental monitoring, plant breeding, soil erosion, food traceability, and use of various analytical techniques for characterization of materials and cultural heritage objects. Additional activities are carried out in the frame of projects arising from the specific needs and requests by MSs.

Some of these courses are organized in cooperation with other IAEA units, such as the Terrestrial Environment Laboratory (TEL), the Radioisotope Products and Radiation Technology Section (RPRT), or the Division of Nuclear Security (NSNS), as well as with the International Centre for Theoretical Physics (ICTP, Trieste, Italy) or other collaborating institutions, such as EST and RBI (see $\S$ IV).

Recent Training courses included:

- Group Fellowship Training (GFT) in nuclear instrumentation (12 weeks, NSIL);

- GFT on X-ray Fluorescence Techniques and Applications (8 weeks, NSIL);

- Training Workshop on Quality Assurance for Nuclear Spectrometry (1 week, NSIL);

- Workshop on Rapid Prototyping of Internet of Things Solutions for Science with one focus on nuclear instrumentation ( 2 weeks, in collaboration with ICTP);

- Advanced Training on Portable X-ray Spectrometry Techniques for specific applications (1 to 2 weeks), such as the Characterization of Valuable Archaeological Objects and Works of Art (in collaboration with ICTP and EST);

- Training Course on Environmental Monitoring and Mapping (1 week, in collaboration with TEL);

- Training Workshop on Hands-on Operation and Maintenance of Electrostatic Accelerators (1 week, in collaboration with RBI);

- Training Workshop on Electrostatic Accelerator Technologies, Associated Instrumentation and Analytical Techniques (1 week, in collaboration with EST);

- Training Course on Radiotracer Technology (2 weeks, in collaboration with RPRT), which is part of a certification diploma for practitioners;

- Training in the Utilization of UAV-based Monitoring System and Data Analysis (2 weeks)

- Training Workshop on the Use of In-field Nuclear Instrumentation for Security Purposes (2 weeks, with NSNS).

NSIL is also cooperating with MSs' institutions that organize national or regional training courses in the frame of TC projects. While the TC Department provides financial support to the course as well as supply off training kits and equipment, NSIL provides scientific and pedagogical assistance to these organizing institutions. Recent and coming courses include:

- Regional Training on Validation of X-ray Emission Techniques for the Analysis of Air Particulate Matter for African laboratories (2 weeks, May 2017, NSIL, Seibersdorf);

- Regional Training Course on Operation and Use of Detectors in Radiation Technologies and Measurement Applications (2 weeks, November 2018, see Fig.1) at Nuclear Research Centre, Egyptian Atomic Energy Authority, Cairo, Egypt.

- National Training Course on Rapid Prototyping of Low Power Sensing Systems (1 week, November 2018) Khartoum, Sudan;

- Regional Training Course for European Laboratories on Quality Assurance in using Nuclear Techniques and for Elemental Analysis of Airborne Particle Matter (2 weeks, December 2018, NSIL, Seibersdorf);

- Regional Fellowship Training in Nuclear Instrumentation (3 weeks, September 2019) at the Centre of Nuclear Research, COMENA, Birine, Algeria.

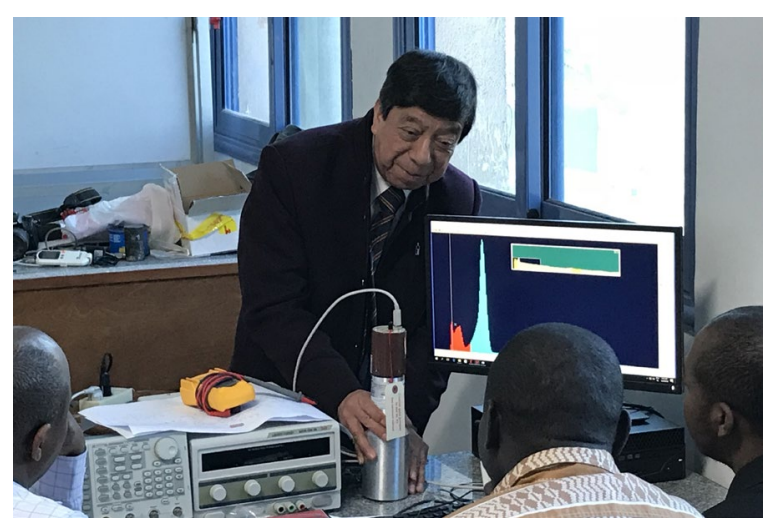

Fig. 1. Regional training course on operation and use of detectors in radiation technologies and measurement applications. Training course organized by the Nuclear Research Centre, Egyptian Atomic Energy Authority, Cairo, Egypt, in cooperation with the IAEA and with the support of international experts. 
CRPs are another tool that can be used for capacity building. These projects bring together research institutes from both developing and developed Member States to collaborate on research topics of common interest. A recent CRP on "Portable detectors for fast environmental mapping" joined participants from eight MSs. A new CRP, "Facilitating Experiments with Ion Beam Accelerators", has been initiated in 2019 to provide access to Ion Beam Analysis (IBA) techniques to scientists from MSs without such capabilities. For the next five years, this project will facilitate and provide financial support for about 15 IBA experiments per year all over the world.

IAEA is producing reference materials, developing standardized analytical methods, and conducting interlaboratory comparisons and proficiency tests as tools for quality assurance and quality control of analytical results. To fulfil this obligation and ensure a reliable, rapid and consistent response, NSIL organizes and coordinates, since 2002, periodic proficiency tests for laboratories using nuclear and related analytical techniques. In 2018, two exercises were organized. The first was committed to the characterization of a "urban dust deposited on filter" sample with nuclear and related analytical techniques (43 laboratories from $33 \mathrm{MSs}$ joined the test); the second was open only to NAA laboratories which were asked to determine elemental concentrations of a biological and a geological sample (41 laboratories from 29 MSs joined the test). An ongoing test is open to laboratories using nuclear and related analytical techniques, which are asked to characterize a biological sample (75 laboratories from 46 Member States accepted the invitation to take part in the test).

\section{ADAPTATIVE RESEARCH AND DEVELOPMENT}

NSIL is performing adaptative research and development targeted at specific needs of the MSs. Hereafter are described two undergoing developments of new instruments and techniques.

Following the Fukushima accident, the Fukushima Prefecture, Japan, launched a project with the IAEA for the development of light gamma radiation monitoring systems onboarded on a UAV for in situ environmental monitoring. Two different detection systems were developed by NSIL. A Geiger-Müller dose rate meter, weighting about $600 \mathrm{~g}$, used for a first assessment of the zone to be measured and a gamma spectrometer based on a $\mathrm{LaBr}$ scintillator coupled to a PhotoMultiplier Tube (PMT). This second system provides isotope identification, though its higher weight limits the flight duration. In both cases, the detection system communicates with the UAV and records the flight parameters, such as the GPS position and altitude. These parameters, combined with the detector signal, are needed for the analysis of the data and establishment of the dose rate mapping.

Two set of UAV monitoring systems, which can be alternatively equipped with the two detection systems, have been produced by NSIL. One set, shown in Fig. 2, has been provided to Japan and used for environmental measurement campaigns at some restricted areas of the Fukushima Prefecture. The UAV's Radio-Controller (RC) provides direct reading of the dose rate, which is used by the pilot to adjust the flight plan according to the characteristics of the monitored area.

The second set of equipment is operated by NSIL and can be used at the request of MSs for measuring campaigns or to conduct trainings or demonstrations on the use of radiation monitoring system onboard UAVs. For example, in October 2018, IAEA experts delivered lectures and performed live action demonstrations of the UAV monitoring system, sharing experience and good practices with various Brazilian institutions.

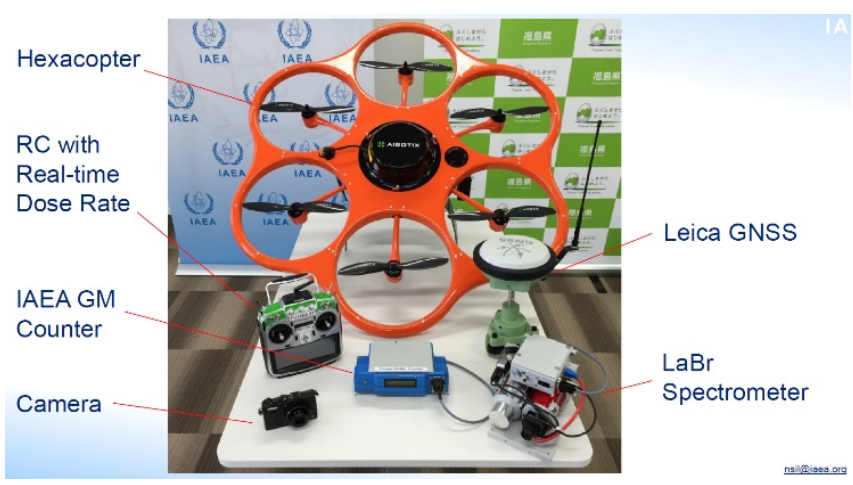

Fig. 2. Set of equipment provided to Japan, it includes two types of detection systems, based on GM and $\mathrm{LaBr}+\mathrm{PMT}$ detectors. The RC of the UAV exhibits a real time dose rate reading.

Taking advantage of the technological advances in detector technology and electronics, an upgraded version of the radiation monitoring system is under progress at NSIL. Recent progress in Silicon Photo-Multipliers (SiPMs), which are much lighter than PMTs and need only $30 \mathrm{~V}$ bias supply, provides a great opportunity to reduce the weight of the entire detection system. This allows the design of dose rate meters based on a $\mathrm{NaI}(\mathrm{Tl})$ scintillator coupled on $\mathrm{SiPMs}$, which provides more accurate dose rate measurement than GeigerMüller detectors with similar overall weight. The use of a scintillator with high resolution (about 3-4 \%, such as $\mathrm{LaBr}(\mathrm{Tl})$ and $\operatorname{SrI}(\mathrm{Eu})$ ) coupled with SiPMs leads to a relatively light gamma spectrometer with good performance. Indeed, the overall weight of the monitoring system, targeted to be less than $1 \mathrm{~kg}$, is an important parameter as it determines the duration of the flight of the UAV.

Another important aspect of the upgrade concerns the implementation of the GPS and altitude sensors in the monitoring system to make it independent from the UAV. Having a system that can be onboarded on any UAV hired with its pilot in the country will overcome the difficulties encountered with shipment of the UAV, including its batteries, and with conforming to UAV flight regulations worldwide.

X-ray fluorescence analysis at NSIL has been applied to a variety of studies: e.g. classification of Sri Lankan tea based on their region of origin [7]; study of surface alterations in archaeological coins [8] and other studies. A full-field XRF spectrometer was commissioned at NSIL. The instrument allows recording 2D elemental distributions in valuable samples without the need for complex translation/scanning systems. It has been tested in the analysis of gunshot residues adhered to the areas surrounding entry orifices and to identify the coloring elements used in archaeological ceramic glazes (see Fig.3).

A procedure to determine the shape and size of the volume probed in confocal XRF analysis was recently developed based in the measurement of micro-sized particles [9]. 


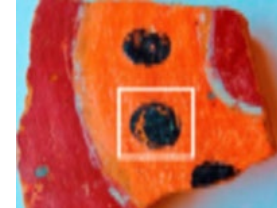

a)

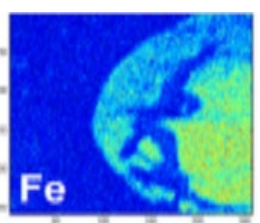

b)

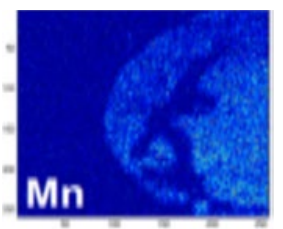

c)
Fig. 3. Elemental maps resulting from the inspection of one ceramic shard: a) optical image; b) Fe-content, c) Mn content

\section{FACILITATING THE ACCESS TO ACCELERATORS}

NSIL is involved in the development and operation of dedicated measurement chambers at beam lines of EST and RBI, facilitating their access to researchers from developing MSs.

NSIL jointly operates with EST a multipurpose X-ray spectrometry end-station at the XRF beamline $(10.1 \mathrm{~L}$, seen in Fig. 4). The facility has been available to external users since the beginning of 2015, initially through a dedicated CRP and then through the bilateral agreement and standard EST peerreview process. Using this collaboration framework, the IAEA supports and promotes synchrotron-radiation-based research and training activities for various research groups from MSs, especially those who have limited previous experience and resources to access a synchrotron radiation facility. The CRP participants originating from seventeen countries all over the world (4 from Asia-Pacific, 2 from the Middle East, 1 from North America, 1 from Latin America and the rest from Europe) have obtained experimental research results of high-quality tackling challenging interdisciplinary applications such as: characterization of structured novel materials for energy storage and conversion technologies, biosensing technologies and nanomedicine design, environmental monitoring of contaminants in air, toxic elements in water and biological specimens, cultural heritage and preventive conservation, food products security and study/improvement of the current level of knowledge concerning fundamental X-ray interactions and parameters.

The IAEA-EST end-station works with monochromatic $\mathrm{X}$-rays in the energy range $3.7-14 \mathrm{keV}$ from the EST storage ring operating at 2.0 or $2.4 \mathrm{GeV}$ electron energy. It offers a combination of different advanced analytical probes, e.g. Xray reflectivity, X-ray absorption fine-structure measurements, grazing-incidence X-ray fluorescence measurements, using different excitation and detection geometries, and thereby supports a comprehensive characterization for different kinds of nanostructured and bulk materials.

NSIL also operates a "mirror end-station", a replication of the chamber installed at EST, in Seibersdorf. The replica is equipped with an X-ray tube coupled with optics to obtain a parallel beam. The system is used to train future users before measuring campaign at EST and to carry out pre-test of new devices and data acquisition systems to be installed at EST.

Since 1997, the IAEA has a bilateral agreement with RBI in Croatia, collaborating for the development and utilization of the Laboratory for Ion Beam Interactions (LIBI), which hosts two tandem electrostatic accelerators with 1 and $6 \mathrm{MV}$ terminal voltage. The facility comprises nine beamlines, including a beamline dedicated to diverse ion beam analysis measurements, constituting the main part of the IAEA-RBI agreement. This beamline was recently upgraded to a dual beam line, i.e. beams from both tandem accelerators can simultaneously and independently be used in the experimental chamber (see Fig. 5). The beamline is equipped with microbeam lenses and collimators that permits to reduce the spot size of the $1 \mathrm{MV}$ accelerator down to micrometer size

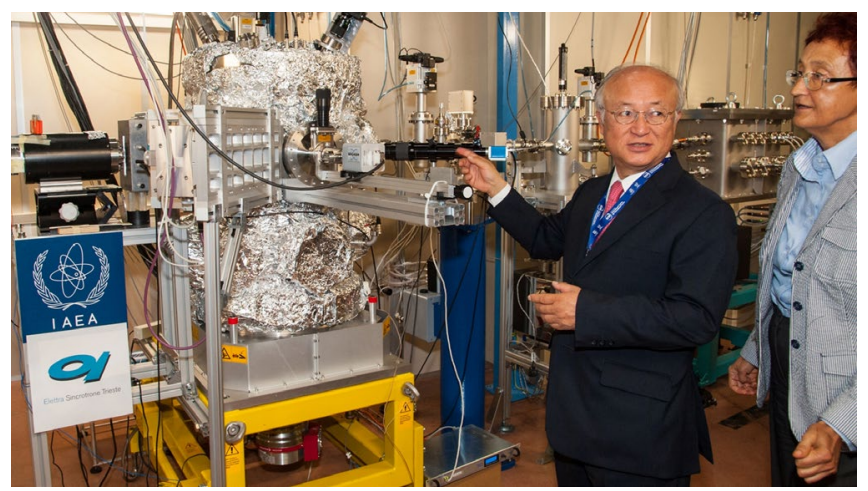

Fig. 4. IAEA Director General Yukiya Amano during the inauguration of the new XRF beamline at EST, in October 2014. (Photo: EST)

(typically, 1 to $10 \mu \mathrm{m}$ ). The second beamline will also be equipped with such microbeam components for the $6 \mathrm{MV}$ accelerator in the near future. The dual beam experimental chamber is equipped with a piezo xyz-translator stage, silicon drift X-ray detector, high purity germanium gamma detector and silicon particle detector. The chamber can be used for micro Particle Induced X-ray and gamma-ray Emission (PIXE and PIGE), Rutherford and Electron Back Scattering (RBS and EBS), as well as off-axis Scanning Transmission Ion Microscopy (STIM) measurements. Specific access to this beamline for IAEA and MSs' scientists is provided.

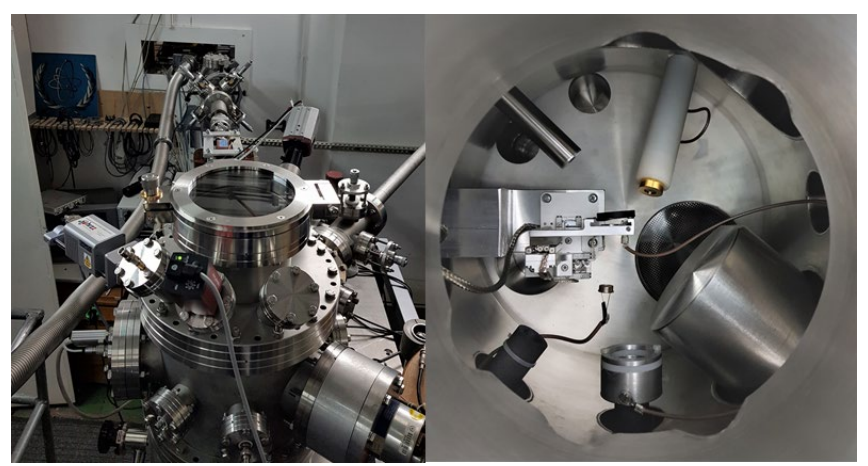

Fig. 5. IAEA dual beam experiment at RBI.

Some recent results of experiments at RBI include the determination of trace elements in rice plants in support of compositional classification to predict tolerance of varieties to salinity stress [10] as well as the analysis of airborne particulate matter for identifying sources of air pollution in Mongolia [11].

At the beginning of 2019 , a negative helium ion source was commissioned at RBI, with the financial and technical support of NSIL. This upgrade will improve the quality of dual beam implantations dedicated to research activities on nuclear fusion materials as part of the IAEA fusion sub-programme implemented by Physics Section.

\section{NEUTRON SCIENCE FACILITY}

The establishment of the Neutron Science Facility (NSF) will expand NSIL capabilities to assist MSs utilizing and developing the peaceful use of nuclear techniques and related 
applications based on neutrons. A survey on "Neutron Generators for Analytical Purposes" [12] has identified a large number of applications of neutron generators in the field of education and training, nuclear data measurements, art and archeology, environment, geology, industry, medicine, nutrition, safeguard and security (see Table 1).

TABLE I. NEUTRON APPLICATIONS IDENTIFIED IN [12]

\begin{tabular}{|c|c|}
\hline Fields & Examples \\
\hline $\begin{array}{l}\text { Education and } \\
\text { training }\end{array}$ & $\begin{array}{l}\text { Neutron activation analysis, neutron physics, } \\
\text { radioprotection, } \\
\text { neutron radiography/tomography, modelling, etc. }\end{array}$ \\
\hline Research & Nuclear data: production rates and cross-sections \\
\hline $\begin{array}{l}\text { Art, } \\
\text { Archaeology }\end{array}$ & $\begin{array}{l}\text { Analysis of artefacts and archeological objects } \\
\text { (major components) }\end{array}$ \\
\hline Environment & $\begin{array}{l}\text { Analysis of recycled materials }(\mathrm{Cd}, \mathrm{Hg}, \mathrm{Br}, \mathrm{Cl}) \text {, } \\
\text { waste materials } \\
\text { Detection of pesticides (halogens } \mathrm{Br}, \mathrm{Cl}, \mathrm{F})\end{array}$ \\
\hline Geology & $\begin{array}{l}\text { On-line analyzers (ash value of coal, calorific } \\
\text { value), exploration (downhole inspection/oil, H), } \\
\text { boron determination, U and Th measurements }\end{array}$ \\
\hline Industry & $\begin{array}{l}\text { On-line analyzers (cement process, coal and mining } \\
\text { industry), metal cleanliness (oxygen in } \mathrm{Mg}, \mathrm{Al} \text {, } \\
\text { Steel), raw materials (purity, contaminants), } \mathrm{Al} \\
\text { based catalysts (F), energy production and storage } \\
\text { (H in fuel cells, Li batteries) }\end{array}$ \\
\hline Medicine & $\begin{array}{l}\text { Biological sample screening }(\mathrm{C}, \mathrm{O}, \mathrm{N}, \mathrm{Ca}, \mathrm{Na}, \mathrm{Cl} \text {, } \\
\mathrm{P})\end{array}$ \\
\hline Nutrition & $\begin{array}{l}\text { Protein content of food }(\mathrm{N}) \text {, animal fodder (trace } \\
\text { elements) }\end{array}$ \\
\hline Safeguards & $\begin{array}{l}\text { Detection of nuclear materials (U, Pu and other } \\
\text { fissile actinides; enrichment) }\end{array}$ \\
\hline Security & $\begin{array}{l}\text { Detection of explosives (cargo/luggage inspection, } \\
\text { suspicious objects), chemical weapons }(\mathrm{N}, \mathrm{P}) \text {, } \\
\text { contraband materials/objects (narcotics, } \mathrm{C}, \mathrm{O}, \mathrm{N})\end{array}$ \\
\hline
\end{tabular}

The NSF will have two compact neutron generators, a DD (resulting in $2.45 \mathrm{MeV}$ neutrons) and a DT (resulting in 14 $\mathrm{MeV}$ neutrons) generator, both providing a neutron yield up to $10^{8} \mathrm{n} / \mathrm{s}$ over $4 \pi$. A consultancy meeting on the establishment of the NSF was organized at the IAEA in December 2018. International experts from $7 \mathrm{MSs}$ shared their experience and feedback on the implementation and utilization of neutron generators for research and various applications providing additional input to the project for its effective implementation that started in 2019.

Figure 6 shows the preliminary layout of the shielding for the DT generator to be installed in a room with low-density concrete walls (in blue). The shielding includes ordinary concrete (in purple) and two layers of materials, denoted Layer 1 and Layer 2, chosen to be either borated polyethylene (5\% boron content) or ordinary concrete, for different sets of calculations of the neutron and photon attenuation. When the DT generator is operated at its maximum yield $\left(10^{8} \mathrm{n} / \mathrm{s}\right)$, dose rates below $10 \mu \mathrm{Sv} / \mathrm{h}$ (in the experimental room, restricted area) and $2.5 \mu \mathrm{Sv} / \mathrm{h}$ (for the public area with limited access) are targeted, except on the of the room which is not accessible in normal circumstances.

Figure 7 shows the result of MCNP Monte Carlo calculations performed with Layers 1 and 2 being both borated polyethylene for the maximum yield of the DT generator. This configuration gives the optimized results in terms of overall neutron and photon attenuation. The maximum dose rate in surrounding public areas is on the order of $1 \mu \mathrm{Sv} / \mathrm{h}$ for neutron and $0.7 \mu \mathrm{Sv} / \mathrm{h}$ for photon radiation. The overall dose rate in the experimental room is ensured below $10 \mu \mathrm{Sv} / \mathrm{h}$.
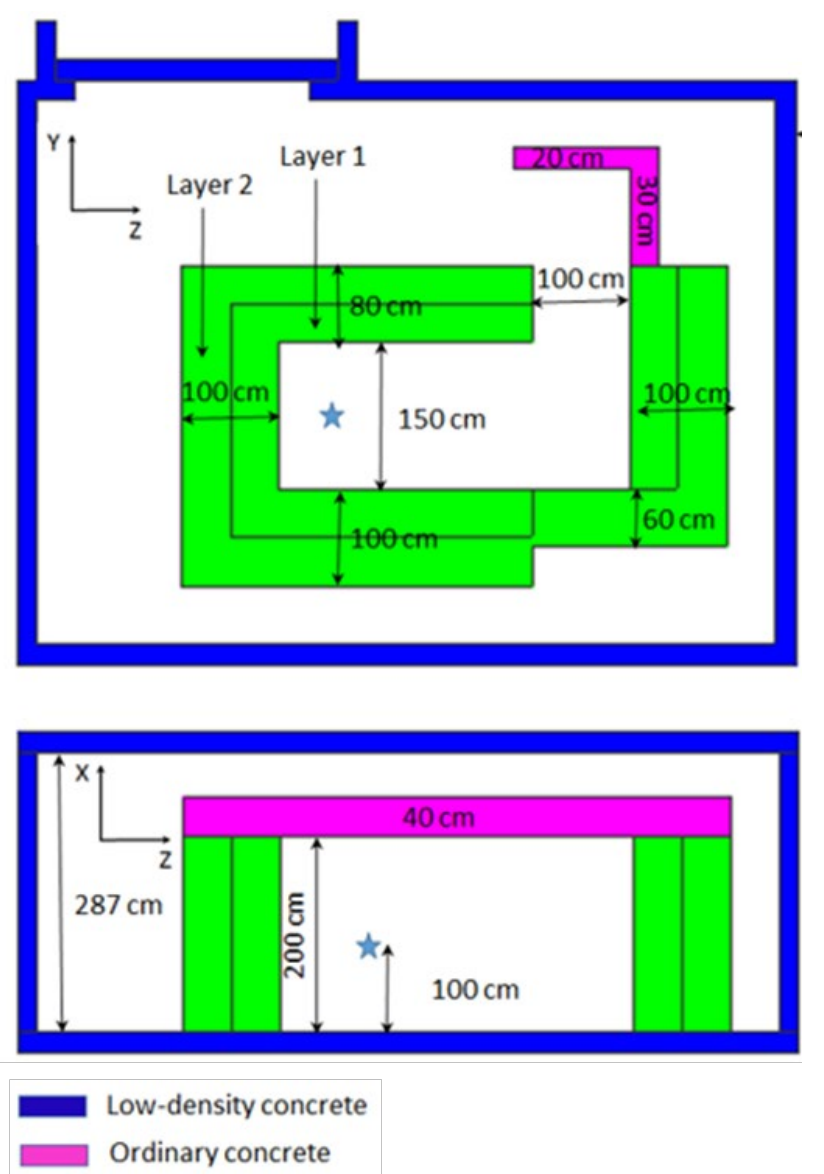

Fig. 6. Top (upper schematic) and side (lower schematic) views of the layout of the shielding for the DT generator. Layer 1 and Layer 2 have been chosen to be either borated polyethylene ( $5 \%$ boron content) or concrete for different sets of Monte Carlo calculations.
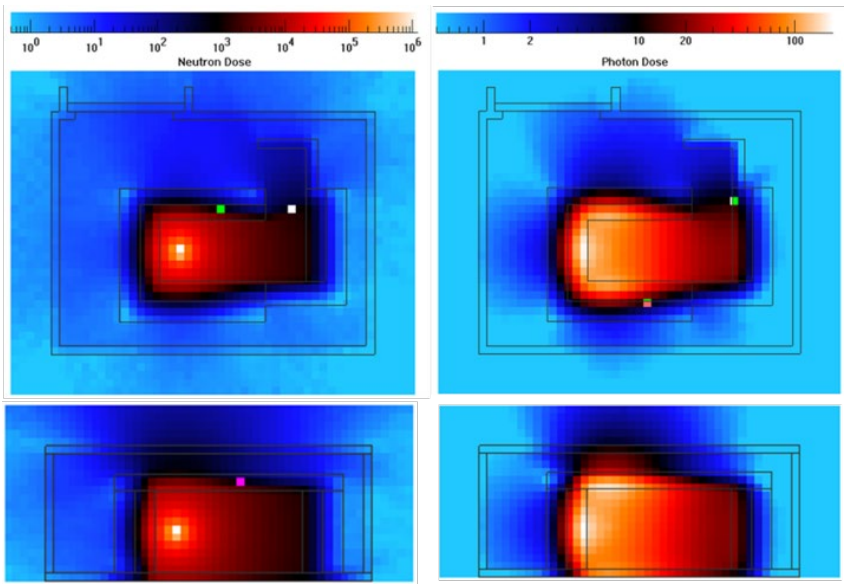

Fig. 7. Calculated dose rate distribution resulting from neutron and photon radiation when the DT generator is operated at its maximum yield $\left(10^{8} \mathrm{n} / \mathrm{s}\right)$, with Layer 1 and 2 being composed of borated polyethylene.

At this stage, this project benefits from donations from three MSs, namely, Australia, United Kingdom and United States.

The implementation of the facility will be performed through a step-wise approach with the successive deployment of the following experiments and services:

- Radiation protection with neutron and gamma fields;

- Neutron instrumentation (including the one utilized in the Instrumentation \& Control systems relevant to research reactors); 
- Operation \& Maintenance of neutron facility based on DD/DT generators;

- Neutron Activation Analysis (NAA);

- Neutron radiography (and tomography);

- Demonstration of radiotracer production and usage;

- Prompt Gamma Activation Analysis (PGAA)

- Neutron physics with $14 \mathrm{MeV}$, fast and thermal neutrons;

- Non-destructive testing using active interrogation;

- Flow loop for radiotracer experiments.

With expected additional extrabudgetary contribution from the IAEA MSs, the implementation of the NSF is planned to be completed by the end of 2021 .

\section{ION BEAM ACCELERATOR PROJECT}

In 2018, the IAEA Physics Section has conducted a feasibility study regarding the establishment of a small Ion Beam Accelerator facility at IAEA Laboratories in Seibersdorf. Analysis of MSs current needs for training and services was conducted based on the evaluation of interviews given by IAEA internal stakeholders and a questionnaire completed by external stakeholders; more than 60 replies from almost 40 MSs were received.

The survey showed a high interest in providing capabilities as shown in Fig. 8. The most commonly demanded topics include:

- Training in Ion Beam Analysis (IBA) techniques; accelerator technology (ion sources, vacuum systems) and end stations (design and assembly, radiation detectors, control systems and nuclear electronics).

- Services relevant to IBA for bulk analysis of air pollution, environmental and trace elements in reference materials, nuclear microprobe applications, such as micro-PIXE or RBS, and Nuclear Reaction Analysis for particulate reference materials.

- Applied research using IBA for homogeneous bulk analysis of air quality, archaeological samples, minerals; 2\&3D imaging and spatially resolved analysis using a microprobe.
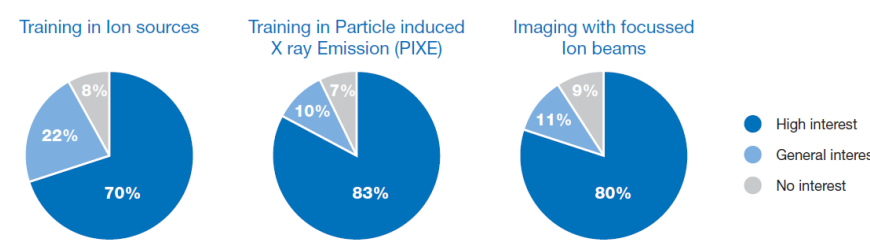

Fig. 8. Level of interest for applications of an Ion Beam Accelerator at IAEA Laboratories, according to the feasibility study conducted in 2018.

Following a comprehensive analysis of the needs, it was concluded that the two most cost-effective options are 1.7 and $3 \mathrm{MV}$ Tandem accelerators. Both cover a broad range of $\mathrm{MeV}$ ion beam applications, the $3 \mathrm{MV}$ Tandem being more versatile and offering further applications as presented in Table 2.

The Physics Section of the IAEA is not able to fund an ion beam accelerator project via its regular budget, and therefore seeks in-kind contributions through extrabudgetary funding and in-kind donations of the entire facility or partial components of equipment.
TABLE II. TARGETED ION BEAM APPLICATIONS AND TECHNIQUES AS WELL AS PROPOSED ACCELERATOR OPTIONS, WITH THEIR RESPECTIVE CAPABILITIES, FOLLOWING THE FEASIBILITY CONDUCTED IN 2018.

\begin{tabular}{|c|c|c|}
\hline \multirow{2}{*}{$\begin{array}{l}\text { Ion beam applications } \\
\text { (Ion beam techniques) }\end{array}$} & \multicolumn{2}{|c|}{ Tandem capability } \\
\hline & 1,7 MV & $3 \mathrm{MV}$ \\
\hline $\begin{array}{l}\text { Capacity building through education and training } \\
\text { (accelerator technology and ion-beam based } \\
\text { techniques) }\end{array}$ & Full $^{\mathrm{a}}$ & Full \\
\hline $\begin{array}{l}\text { Environmental monitoring - air and water quality } \\
\text { - climate change studies (RBS, PIGE, PIXE, } \\
\text { Micro-Focused Ion Beams) }\end{array}$ & Full & Full \\
\hline $\begin{array}{l}\text { Geological elemental mapping, such as soil or } \\
\text { sediment characterization (RBS, PIGE, PIXE, } \\
\text { Micro-Focused Ion Beams) }\end{array}$ & Full & Full \\
\hline $\begin{array}{l}\text { Analysis of biological samples - toxic element } \\
\text { identification - medicine (PIXE, IBIL, Micro- } \\
\text { Focused Ion Beams, NRA, MeV-SIMS) }\end{array}$ & Full & Full \\
\hline $\begin{array}{l}\text { Analysis of structural materials for energy } \\
\text { applications including fusion (RBS, PIGE, PIXE, } \\
\text { NRA, IBIC, IBIL) }\end{array}$ & Full & Full \\
\hline $\begin{array}{l}\text { Cultural heritage studies (RBS, PIGE, PIXE, } \\
\text { Micro-Focused Ion Beams, external Micro- } \\
\text { Focused Ion Beams) }\end{array}$ & Full & Full \\
\hline $\begin{array}{l}\text { Neutron production complementary to other } \\
\text { facilities at SEIB (via low energy } \mathrm{p}+\mathrm{Li} \text { reaction) }\end{array}$ & Full & Full \\
\hline $\begin{array}{l}\text { Dosimetry and cancer research (high energy ion } \\
\text { beam irradiations) }\end{array}$ & Partial $^{\mathrm{b}}$ & Partial \\
\hline $\begin{array}{l}\text { Nuclear data for various fields of nuclear } \\
\text { technology (all ion beam techniques) }\end{array}$ & Partial & Partial \\
\hline $\begin{array}{l}\text { Multilayer analysis, depth profiling, 3D imaging } \\
\text { of materials of technological interest (RBS, EBS, } \\
\text { Micro-Focused Beams, ToF-ERDA) }\end{array}$ & Partial & Full \\
\hline $\begin{array}{l}\text { Materials modification and testing by irradiation, } \\
\text { including materials for energy applications, } \\
\text { irradiation of semi-conductors, space electronics, } \\
\text { etc. (high energy proton and heavier ion beam } \\
\text { irradiations and characterizations) }\end{array}$ & Partial & Full \\
\hline $\begin{array}{l}\text { Surface analysis of materials of technological } \\
\text { interest, e.g. photovoltaics (RBS, EBS, Micro- } \\
\text { Focused Ion Beams, ToF-ERDA, MeV-SIMS, } \\
\text { IBIC, IBIL) }\end{array}$ & Partial & Full \\
\hline $\begin{array}{l}\text { Forensic studies: combined techniques applied to } \\
\text { various domains (RBS, EBS, Micro-Focused Ion } \\
\text { Beams, ToF-ERDA, MeV-SIMS) }\end{array}$ & Partial & Full \\
\hline $\begin{array}{l}\text { Food quality \& security - nutrition value } \\
\text { (PIGE, PIXE, Micro-Focused Ion Beams, NRA) }\end{array}$ & Partial & Full \\
\hline $\begin{array}{l}\text { Mutation breeding studies of seeds, plants, rice } \\
\text { etc. (high energy proton and heavier ion beam } \\
\text { irradiations) }\end{array}$ & Limited $^{\mathrm{c}}$ & Partial \\
\hline \multicolumn{3}{|c|}{$\begin{array}{l}\text { Full capability: applicable to all established techniques relevant to a given application, } \\
\text { including those under development without any restrictions; fully compatible for capacity } \\
\text { building. }\end{array}$} \\
\hline \multicolumn{3}{|c|}{$\begin{array}{l}\text { b. Partial capability: applicable for most of the established techniques with some limitations } \\
\text { due to lower energies; fully compatible for capacity building. }\end{array}$} \\
\hline $\begin{array}{l}\text { c. Limited capability: applicability either not possible or yet } \\
\text { energies but could be explored for demonstration purposes }\end{array}$ & ully establi & due to lower \\
\hline
\end{tabular}

\section{CONCLUSIONS}

NSIL's mission is to help IAEA Member States to establish, operate and maintain various nuclear instrumentation and spectrometry techniques in support of a wide range of applications. This is conducted through a large range of capacity building activities with the objective of collecting and sharing knowledge and competences, assisting MSs in developing their own capacity, providing basic to advanced training, facilitating the access to research facilities and conducting proficiency tests as tools for quality assurance and quality control of analytical results. According to MSs' needs NSIL is performing adaptative research and development such as the one conducted for the development of ultra-light gamma monitoring system onboard UAVs. NSIL is collaborating with a number of internal IAEA units 
(TEL, RPRT, NSNS), state- of-the-art facilities (EST, RBI) and international organizations (ICTP), in order to expand its capabilities and outcomes. NSIL is currently installing a neutron science facility based on the utilization of both DD and DT neutron generators. This facility will provide a broad range of experiments and services that will include neutron activation analysis, neutron radiography and demonstration of radiotracer production and usage. NSIL is also seeking support from MSs to install on the NSIL premises a Tandem accelerator, which will further enlarge IAEA's capabilities in offering its MSs needed products and services. With sufficient support to secure the ion beam project, the IAEA at NSIL will be able to offer training, analysis and irradiation opportunities using three complementary probes: X-rays, neutron and ion beams.

\section{ACKNOWLEDGMENT}

We gratefully thank V. Blideanu from the French Alternative Energies and Atomic Energy Commission who performed the MCNP calculations for the shielding of the neutron generators.

\section{REFERENCES}

[1] IAEA TECDOC No. 1706, Instrumentation for Digital Nuclear Spectroscopy, 2013,

https://www-pub.iaea.org/MTCD/Publications/PDF/te_1706 web.pdf

[2] IAEA TECDOC No. 1765, Uso de nuevas tecnologías para el diseño, modernización y automatización de sistemas y procesos relacionados con aplicaciones nucleares, 2016, https://www.iaea.org/es/publications/10831/uso-de-nuevastecnologias-para-el-diseno-modernizacion-y-automatizacion-desistemas-y-procesos-relacionados-con-aplicaciones-nucleares

[3] Introduction to in-situ techniques for radiological characterization of sites, www.pt-nsil.com/insitu

[4] Introduction to X-Ray Emission Spectrometry, www.pt-nsil.com/xrs

[5] Course on Neutron Activation Analysis, https://elearning.iaea.org/m2/enrol/index.php?id=482

[6] Strategic Planning for National Nuclear Institutions, https://elearning.iaea.org/m2/course/view.php?id $=570$

[7] D. Rajapaksha et al., "XRF to support food traceability studies: Classification of Sri Lankan tea based on their region of origin", X-ray Spectrometry, vol. 46, pp. 220-224, 2017.

[8] K. Uhlir et al., "The mystery of mercury-layers on ancient coins - a multianalytical study on the Sasanian coins under the reign of Khusro II", Microchemical Journal, vol. 125, pp. 159-169, 2016).

[9] R. Padilla Alvarez, P. Poths, E. Chinea-Cano, N. Dzigal, J. Osan and I. G. Darby, "Experimental assessment of effectively probed volume in confocal XRF spectrometry using micro-particles", DOI : 10.1002/(ISSN)1097-4539

[10] S. Bado et al., "The application of XRF and PIXE in the analysis of rice shoot and compositional screening of genotypes", Nuc. Instrum. Methods B, vol. 371, pp. 407-412, 2016.

[11] G. Guchin, et al., "Three-Year Long Source Apportionment Study of Airborne Particles in Ulaanbaatar Using X-Ray Fluorescence and Positive Matrix Factorization, Aerosol and Air Quality Research", Aerosol and Air Quality Research, vol. 19 ,pp. 1056-1067, 2019.

[12] IAEA Radiation Technology Report $\mathrm{n}^{\circ} 1$, Neutron Generators for Analytical Purposes, 2012. 